\title{
Rancang Bangun Sistem Pendeteksi Ketinggian Air Jarak Jauh Menggunakan Sensor HC-SR04 dan Modul GSM SIM800L Berbasis Mikrokontroler ATMega 328
}

\section{The Prototype of Water Level Detection System Using HC-SR04 Sensor and GSM SIM800L Module Based on ATMega 328 Microcontroller}

\author{
I Putu Wahyu Pranata Kusuma Jaya ${ }^{1}$, I Gusti Agung Widagda ${ }^{2}$, I Gde Antha \\ Kasmawan $^{3}$ \\ 1, 2, 3 Jurusan Fisika, Fakultas Matematika dan Ilmu Pengetahuan Alam, Universitas Udayana, Kampus \\ Bukit Jimbaran, Badung, Bali, Indonesia 80361 \\ Email:*wahyupranata992@gmail.com; igawidagda@unud.ac.id; anthakas67@unud.ac.id
}

\begin{abstract}
Abstrak - Telah dirancang sistem pendeteksi ketinggian air menggunakan sensor HC-SR04 dan modul GSM SIM800L berbasis Mikrokontroler ATMega328. Penelitian ini bertujuan untuk memantau ketinggian air melalui media indikasi seperti warna LED dan bunyi buzzer yang berbeda. Selain itu, media komunikasi antara pengguna dengan alat rancangan yaitu menggunakan SMS. Pengguna juga dapat mengontrol Relay dan memberi informasi berupa ketinggian air saat ini kepada alat rancangan melalui SMS. Komponen-komponen yang digunakan dalam merancang sistem ini adalah Arduino Uno, sensor HC-SR04, modul GSM SIM800L, LCD, LED, buzzer, regulator step-down. Prinsip kerja dari sistem ini adalah sistem akan mengindikasikan ketinggian air melalui status-status yang telah ditentukan yakni aman, siaga dan bahaya. Setiap status memiliki warna LED serta bunyi buzzer. Ketika ketinggian permukaan air mencapai nilai ambang pada setiap status maka alat rancangan akan mengirimkan pesan kepada pengguna berupa status serta ketinggian air saat ini. Ketika tinggi permukaan air mencapai status bahaya, maka Relay akan menyala dan mati ketika ketinggian permukaan air mencapai status aman. Berdasarkan nilai standar deviasi, alat yang dirancang memiliki standar deviasi yang cukup kecil antara 0-0,2 cm sehingga alat dikatakan cukup presisi. Sedangkan, berdasarkan hasil uji kalibrasi antara jarak yang terbaca pada LCD dengan mistar diperoleh koefisien determinasi sebesar 0,9996 atau 99,96\% dan SMS dengan mistar diperoleh 0,9997 atau 99,97\%. Hal ini menunjukkan bahwa alat yang dirancang memiliki akurasi yang baik.
\end{abstract}

Kata kunci: Arduino Uno, sensor HC-SR04, modul GSM SIM800L, ketinggian permukaan air, SMS.

\begin{abstract}
A prototype of water level detection has been designed using the HC-SR04 sensor and the GSM SIM800L module based on the ATMega328 Microcontroller. This study aims to monitor the water level through indication media such as LED colors and different buzzer sounds. In addition, the communication medium between the user and the design tool is using SMS. Users can also control the Relay and provide information in the form of current water levels via SMS. The components used to design this system are Arduino Uno, sensor HC-SR04, GSM SIM800L Module, LCD, LED, buzzer and Step-Down regulator. The principle of this system is the system will indicate the water level through predetermined statuses, such as safe, alert and dangerous. Each status has a different LED color and buzzer sound. When the water level reaches the threshold value for each status, the design tool will send a message to the user in the form of the current status and water level. When the water level reaches dangerous status, the relay will turn on and off when the water level reaches safe status. Based on the standard deviation value, the designed tool has a fairly small standard deviation between 0-0.2 cm so that the tool is said to be quite precision. Meanwhile, based on the results of the calibration test between the read distance on the LCD and the ruler, the coefficient of determination is 0.9996 or $99.96 \%$ and SMS with the ruler obtained 0.9997 or $99.97 \%$. This indicated that the designed tool has good accuracy.
\end{abstract}

Keywords: Arduino Uno, sensor HC-SR04, modul GSM SIM800L, water surface level, SMS. 


\section{Pendahuluan}

Kemajuan teknologi di era digital ini banyak memudahkan akitivitas masyarakat. Salah satu contohnya di bidang komunikasi. Internet sebagai sarana informasi dan komunikasi adalah yang sangat populer saat ini. Komunikasi melalui media internet dikenal dengan Internet of Thing (IoT). IoT pada zaman revolusi industri 4.0 merupakan bentuk revolusi internet, dimana manusia mampu berinteraksi dengan mesin, demikian juga mesin dengan mesin bisa saling berkomunikasi [1]. Kemajuan teknologi mendorong manusia untuk semakin berinovasi dalam merancang peralatan tepat guna yang mampu dimanfaatkan dalam berbagai sektor kehidupan, salah satunya yakni kemudahan dalam memantau ketinggian permukaan air.

Masih banyak masyarakat yang belum mampu melakukan kegiatan pemantauan ketinggian air secara tepat dan mudah. Hal ini dikarenakan kegiatan pemantauan kuantitas air masih terbilang cukup sulit dilakukan secara langsung atau real time [2]. Berdasarkan uraian tersebut, perlu dirancang alat pendeteksi ketinggian permukaan air jarak jauh, yang nantinya bisa dipantau secara real time. Kegiatan pemantauan ketinggian air ini diharapkan dapat mengurangi potensi dari kerugian yang disebabkan dari kuantitas air yang tidak proporsional sehingga dapat mencegah kerugian yang diakibatkan dari kuantitas air yang tidak proporsional [3].

Penelitian ini akan dirancang sebuah sistem pendeteksi ketinggian air jarak jauh menggunakan sensor HC-SR04 dan modul GSM SIM800L berbasis mikrokontroler ATMega328. alat yang dirancang bersifat user friendly, dapat mengirimkan pesan status ketinggian air saat ini, serta tinggi permukaan air dari sensor, sehingga dapat meminimalisir kerugian yang ditimbulkan. Alat yang dirancang juga menggunakan LED yang memiliki perbedaan warna pada setiap level ketinggian yaitu warna merah untuk status bahaya, warna kuning untuk status siaga, serta warna hijau untuk status aman. Alat rancangan juga dilengkapi dengan buzzer sebagai alarm yang diatur untuk menghasilkan bunyi yang berbeda pada setiap status ketinggian. Alat rancangan ini dihubungkan dengan Relay, dimana berfungsi sebagai saklar untuk mengendalikan mesin penyedot air, yang akan aktif saat ketinggian air berada pada status bahaya, dan mati saat status ketinggian air berada pada level aman. Pengguna juga dapat mengatur Relay dengan menggunakan ponsel via SMS.

\section{Landasan Teori}

\subsection{Sensor Ultrasonik HC-SR04}

Sensor HC-SR04 merupakan sensor yang mampu mengukur jarak. Sensor ini juga disebut sebagai sensor ultrasonik [4]. Sensor ultrasonik terdiri atas transmitter dan receiver yang berperan dalam mengirimkan, menerima dan mengatur gelombang ultrasonik [5]. Prinsip kerja sensor HC-SR04 adalah transmitter memancarkan gelombang ultrasonik, jika di depan sensor HC-SR04 terdapat objek maka gelombang ultrasonik akan dipantulkan. Waktu yang dibutuhkan dari sinyal dipancarkan hingga kembali ke receiver diukur. Receiver akan membaca lebar pulsa yang dipantulkan objek dan perbedaan waktu pemancaran. Prinsip kerja sensor HC-SR04 ditunjukkan oleh Gambar 1a) dan bentuk fisiknya diperlihatkan pada Gambar 1b).
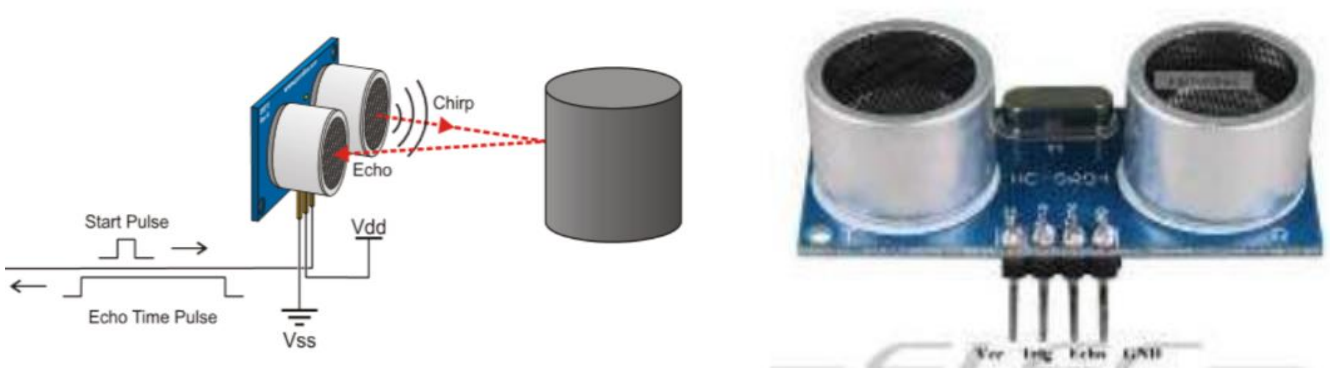

Gambar 1. a). Prinsip kerja sensor HC-SR04, b). Bentuk fisik sensor HC-SR04 [6].

\subsection{Arduino Uno}

Mikrokontroler adalah komponen elektronika digital yang memiliki input dan output serta dikendalikan menggunakan program yang dapat ditulis dan dihapus dengan cara tertentu. Mikrokontroler tersusun dalam satu chip dimana prosesor, memori, dan input/output tersusun menjadi satu kesatuan kontrol sistem yang mampu bekerja menurut kebutuhan sistem [7]. Pada penelitian ini, Arduino Uno digunakan 
sebagai mikrokontroler untuk mengolah data nantinya. Arduino Uno merupakan sebuah board mikrokontroler berbasis ATMega328. Bentuk fisik Arduino Uno ditunjukkan oleh Gambar 2.

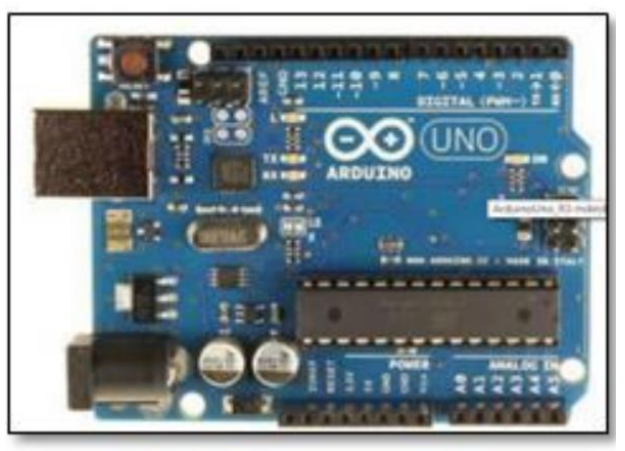

Gambar 2. Bentuk fisik Arduino Uno [7].

\subsection{Liquid Crystal Display (LCD) 16x2}

LCD adalah salah satu jenis display yang diciptakan menggunakan teknologi Complementary MetalOxide Semiconductor (CMOS) logic yang prinsip kerjanya yakni dengan tidak menghasilkan cahaya, melainkan meneruskan cahaya dari back-lit. LCD memiliki harga yang terjangkau, dan memiliki keunggulan dapat menunjukkan banyak karakter serta sesuai pada hampir segala mikroprosesor dan mikrokontroler. Bentuk fisik LCD ditunjukkan oleh Gambar 3.

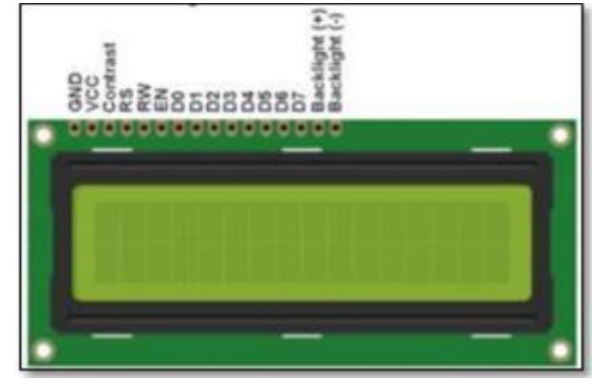

Gambar 3. Bentuk fisik LCD 16x2 [7].

\subsection{Modul GSM SIM800L}

Modul SIM800L adalah komponen elektronika yang berfungsi untuk berkomunikasi antara sistem pendeteksi ketinggian air dengan Handphone. Sebuah Modul GSM SIM800L terdiri atas beberapa bagian, antara lain lampu indikator, terminal daya, terminal kabel ke komputer, antena dan slot kartu microSIM. Saat pertama dihubungkan dengan sistem, LED pada GSM SIM800L akan berkedip sekali per detik. Hal tersebut menandakan modul GSM SIM800L sedang mencari sinyal. Ketika LED berkedip sekali setiap 3 detik, maka GSM SIM800L siap digunakan. Untuk lebih jelasnya, pin-out Modul GSM SIM800L ditunjukkan pada Gambar 4.

Dalam mengoperasikan modul GSM SIM800L, diperlukan tegangan masukan berkisar pada 3,7 hingga 4,2 Volt. Sedangkan, tegangan yang diberikan oleh Arduino Uno adalah sebesar 5 Volt [8]. Untuk mengonversi tegangan masukkan pada GSM SIM 800L, dibutuhkan suatu komponen yakni regulator Step-Down. Pengonversi tegangan yang dimaksud adalah regulator Step-Down [9]. Bentuk fisik dari regulator Step Down dapat dilihat pada Gambar 5.

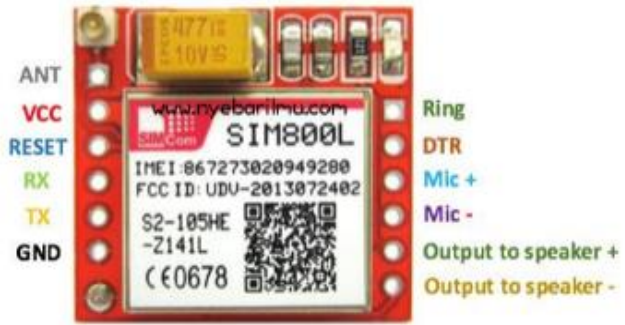

Gambar 4. Bentuk fisik modul GSM SIM800L [10].

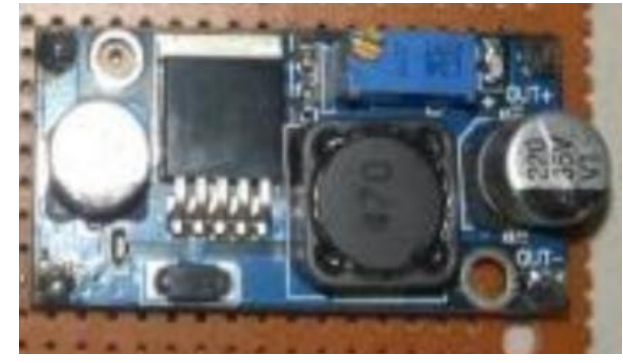

Gambar 5. Bentuk fisik regulator step down [11]. 


\section{Metode Penelitian}

Penelitian dan perancangan sistem pendeteksi ketinggian air jarak jauh menggunakan sensor HC-SR04 dan modul GSM SIM800L berbasis mikrokontroler ATMega328 dilakukan pada bulan Juli 2020 hingga Mei 2021 yang bertempat pada Laboratorium Elektronika dan Instrumentasi, Program Studi Fisika, Fakultas Matematika dan Ilmu Pengetahuan Alam Universitas Udayana.

Adapun alat dan bahan yang digunakan dalam perancangan ini yaitu untuk alat antara lain Arduino Uno, Regulator Step Down, Sensor HC-SR04, modul GSM SIM800L, LCD 16x2, Inter Integrated Circuit (I2C), Resistor 330 Ohm, LED merah, kuning, hijau, buzzer, akrelik, relay. Sedangkan, untuk bahan antara lain solder, seperangkat obeng, penyedot timah, tang, komputer, kabel downloader. Langkah-langkah dalam penelitian dijelaskan pada diagram alir pada Gambar 6.

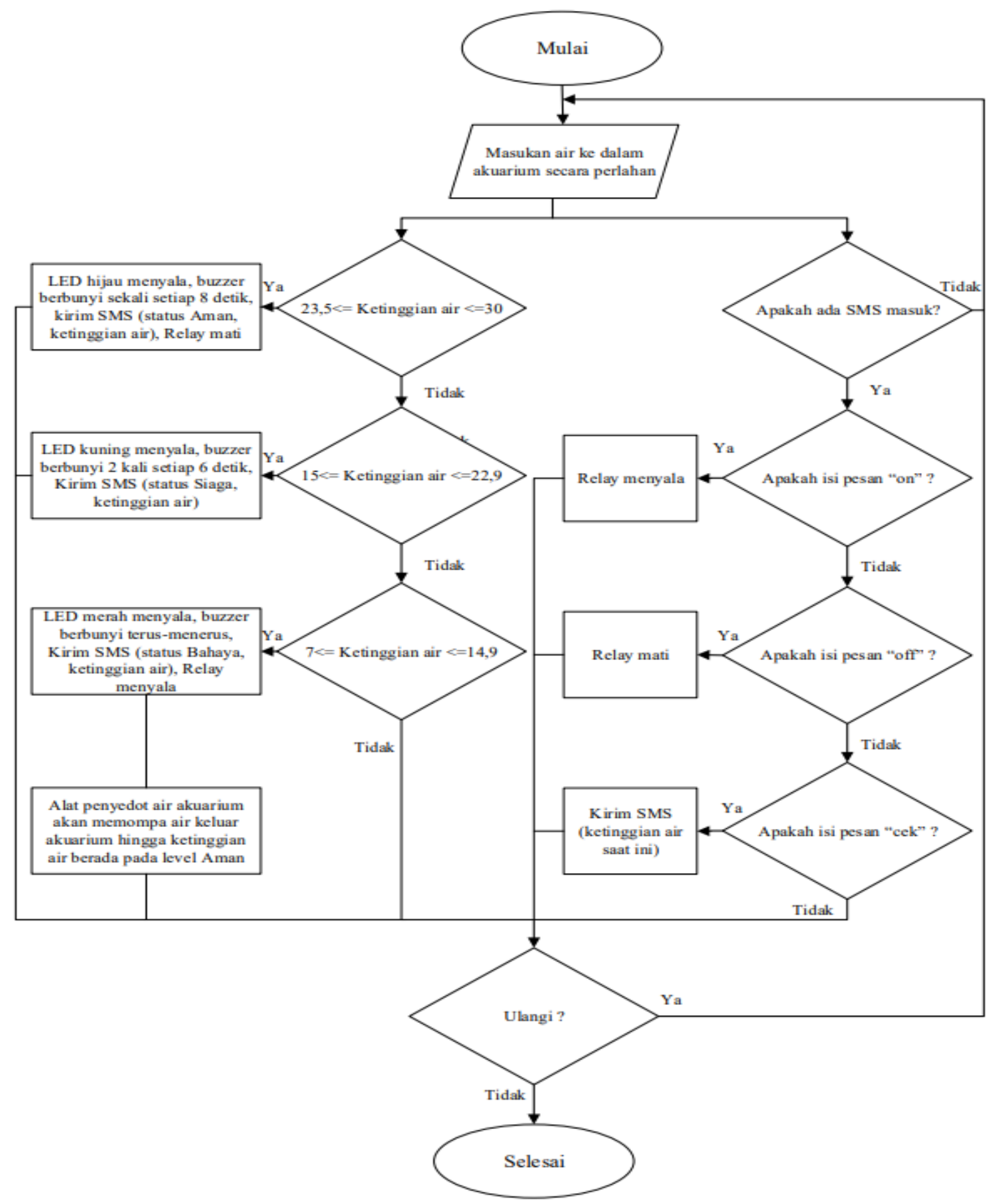

Gambar 6. Diagram alir penelitian. 
Tahap pelaksanaan eksperimen. Pertama, komponen-komponen yang telah dipersiapkan dirangkai. Setelah dirangkai, dilakukan kalibrasi terhadap sensor HC-SR04 yang bertujuan untuk mencari hubungan antara periode waktu sinyal input pulsa HIGH atau yang seterusnya disebut dengan durasi pulsa dengan jarak referensi pada mistar. Kalibrasi dilakukan dengan meletakkan halangan di depan sensor, pada jarak yang telah ditentukan secara bersamaan pada LCD ditampilkan durasi pulsa yang terbaca. Dilakukan pengulangan sebanyak 5 kali selama 60 sekon dengan kenaikan ketinggian setiap $1 \mathrm{~cm}$ terhadap jarak pada mistar. Setelah data durasi pulsa dan jarak referensi diperoleh maka dicari hubungannya dengan metode analisis regresi yaitu regresi linier, dari sini diperoleh persamaan kalibrasi, yang nantinya akan dimasukkan dalam kode program pada sistem untuk diujikan. Setelah proses kalibrasi, alat rancangan diletakkan pada akuarium dan status interval diatur. Adapun interval status-status pada penelitian ini antara lain Aman berada pada interval 23 hingga $30 \mathrm{~cm}$, Siaga berada pada interval 15 hingga 22,9 cm, dan Bahaya berada pada interval 7 hingga $14,9 \mathrm{~cm}$. Setelah alat rancangan dan akuarium dipersiapkan, masukan air secara perlahan-lahan hingga mencapai status-status yang telah disebutkan. Pengamatan pada LCD dilakukan 5 kali dengan pengulangan selama 60 sekon untuk masing-masing jarak, kegiatan serupa dilakukan pada pengamatan melalui SMS, hanya saja pengulangannya tidak dilakukan selama 60 sekon, tetapi dengan mengirimkan pesan "cek" sebanyak 5 kali untuk masing-masing jarak referensi. Data pengamatan dicatat dan dicari nilai standar deviasi untuk mengetahui besar penyimpangan yang terjadi, serta untuk mengetahui akurasi dari instrument yang didesain digunakan metode analisis regresi, yaitu regresi linier.

\section{Hasil Dan Pembahasan}

\subsection{Hasil}

Hasil yang didapat dari penelitian ini adalah sebuah rancang bangun sistem pendeteksi ketinggian air jarak jauh menggunakan sensor HC-SR04 dan modul GSM SIM800L berbasis mikrokontroler ATMega328. Alat ini menggunakan modul GSM SIM800L sebagai media komunikasi antara sistem yang dibuat dengan ponsel pengguna. Sebelum alat rancangan digunakan, alat akan dikalibrasi terlebih dahulu untuk mengetahui kepresisian dan keakuratan dari alat tersebut. Hasil kalibrasi alat antara jarak referensi terhadap durasi pulsa yang terbaca ditunjukkan pada Gambar 7. Data tersebut kemudian dianalisis menggunakan analisis regresi untuk mendapatkan koefisien determinasinya. Hasil analisis regresi juga ditampilkan pada Gambar 7.

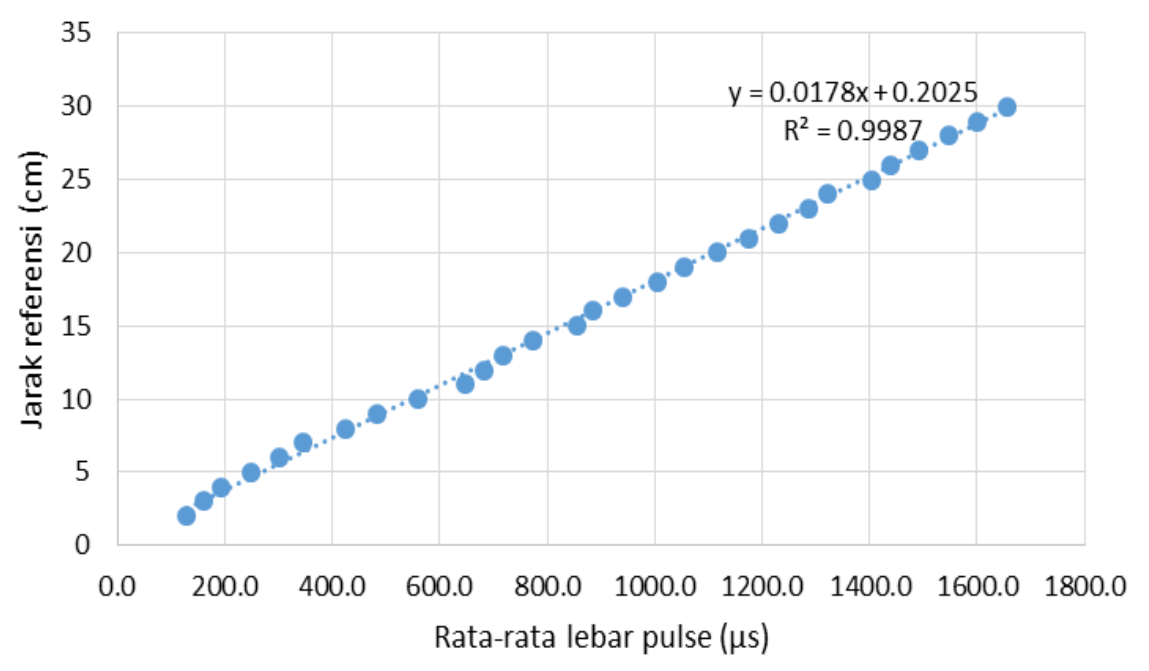

Gambar 7. Grafik analisis regresi kalibrasi rata-rata durasi pulsa dengan jarak referensi.

Berdasarkan Gambar 7, nilai koefisien determinasi $\left(\mathrm{R}^{2}\right)$ adalah 0,9987 yang diartikan sebagai titik-titik datanya 99,87\% yang berdekatan dengan garis regresinya. Hasil regresi inilah yang akan dipakai pada program yang ditanamkan pada mikrokontroler. Alat rancangan selanjutnya diuji dengan membandingkan nilai yang terbaca pada LCD serta SMS yang diterima dengan mistar. Hasil pengujian tersebut kemudian dianalisis dengan analisis regresi untuk mendapatkan persamaan regresi dan koefisien determinasinya. Hasil analisis regresi diperlihatkan pada Gambar 8 (a) dan (b). 


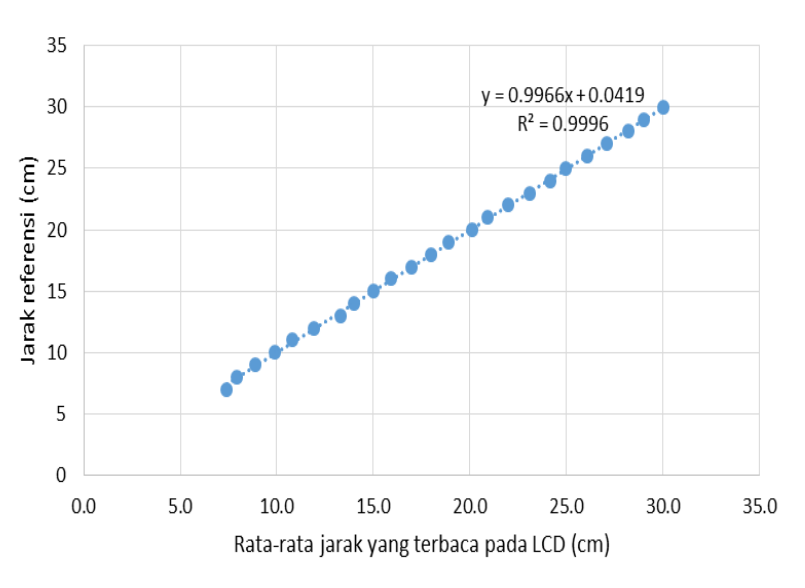

a)

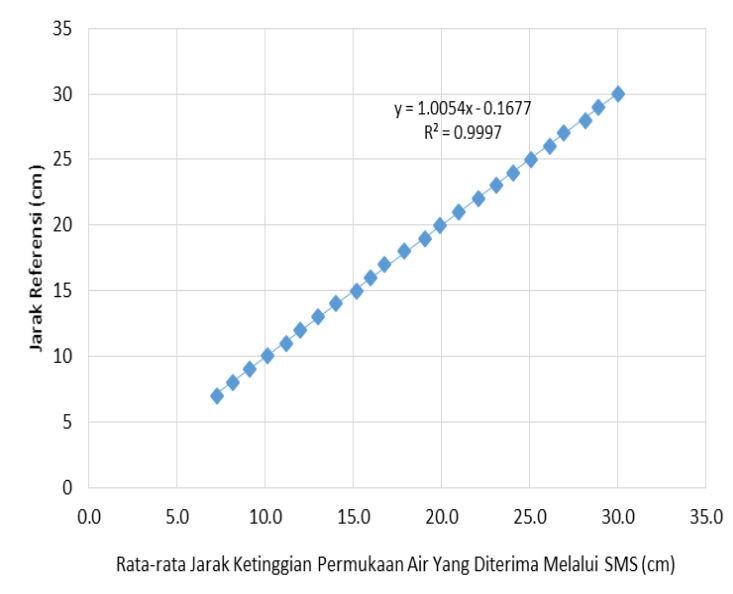

b)

Gambar 8. a) Grafik analisis regresi alat rancangan via LCD dengan mistar. b) Grafik analisis regresi pesan yang diterima oleh pengguna dengan mistar.

Pada Gambar 8 (a), Nilai koefisien determinasi $\left(\mathrm{R}^{2}\right)=0,9996$ untuk pengamatan alat rancangan melalui LCD dan mistar, diartikan sebagai titik-titik datanya 99,96\% yang berdekatan dengan garis regresinya. Pada Gambar 8 (b), nilai $\mathrm{R}^{2}=0,9997$ untuk pengamatan nilai ketinggian permukaan air yang diterima melalui pesan SMS dan mistar, diartikan sebagai titik-titik datanya 99,97\% yang berdekatan dengan garis regresinya. Pada alat rancangan juga didesain ketika pengguna dapat mengendalikan Relay melalui ponsel dimana ketika pengguna mengirimkan pesan "on" maka Relay akan menyala, dan alat rancangan akan mengirimkan pesan "Relay Menyala" sedangkan bila Pengguna mengirimkan pesan "off' maka Relay akan mati, dan akan diterima pesan "Relay mati" oleh pengguna seperti yang ditunjukkan pada Gambar 9.

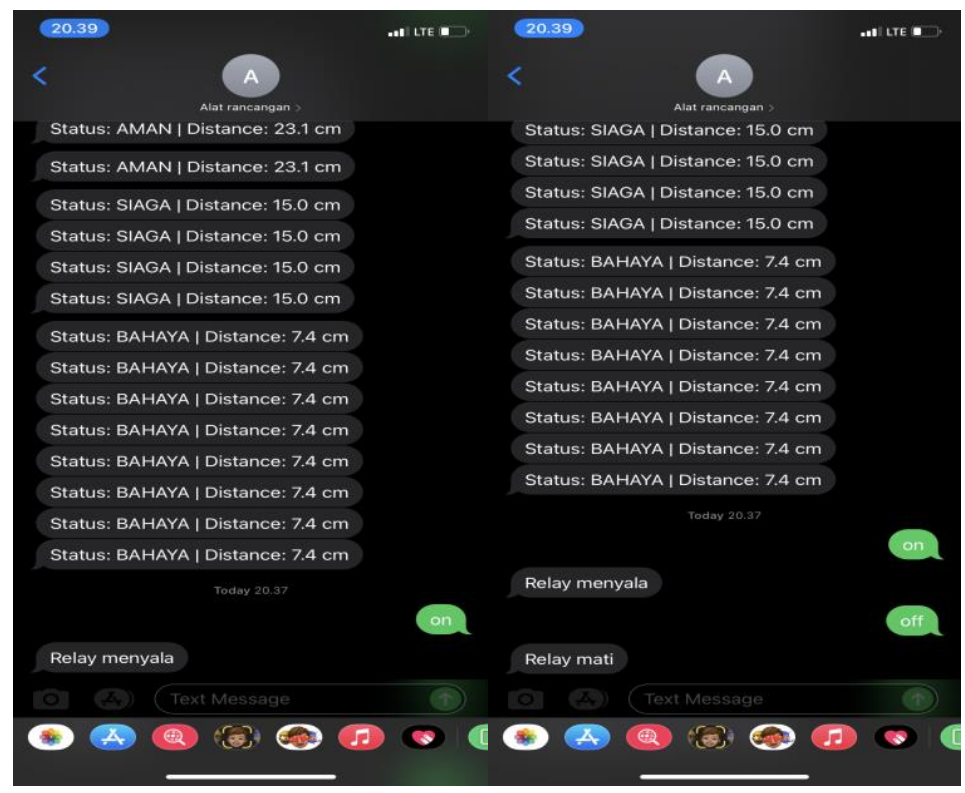

Gambar 9. Proses mengaktifkan dan mematikan relay dengan SMS.

Pengguna juga dapat meminta informasi ketinggian air saat ini dengan mengirimkan pesan "cek", maka alat rancangan akan mengirimkan pesan berupa ketinggian air saat ini ke pengguna seperti yang ditunjukkan pada Gambar 10. 


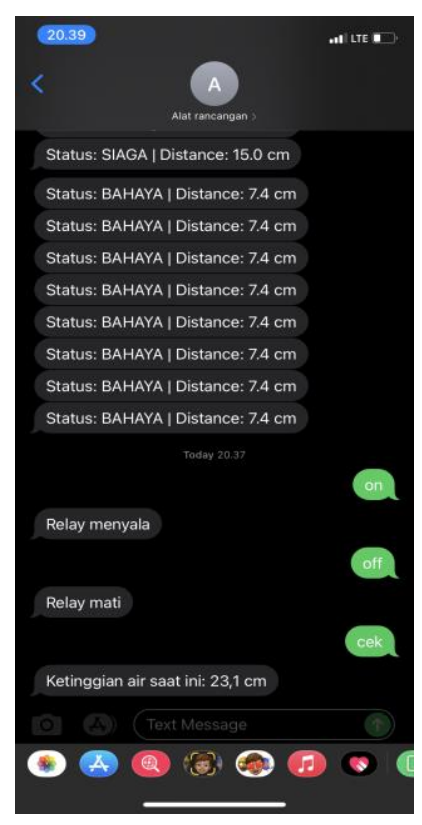

Gambar 10. Alat rancangan mengirimkan pesan ketinggian air saat ini ketika pengguna mengirimkan pesan "cek".

\subsection{Pembahasan}

Telah dilakukan pengamatan terhadap ketinggian permukaan air dengan alat rancangan sistem pendeteksi ketinggian air jarak jauh menggunakan sensor HC-SR04 dan modul GSM SIM800L berbasis mikrokontroler ATMega328, serta mistar. Dilakukan 2 pengujian pada alat rancangan, pertama yaitu pengujian data jarak yang terbaca pada LCD terhadap mistar. Berdasarkan Gambar 8(a), diperlihatkan fungsi linear yaitu setiap kenaikan $1 \mathrm{~cm}$ pada alat rancangan akan meningkatkan 0,99966 pada jarak referensi dan diperoleh konstanta bernilai positif yaitu 0,0419. Hal ini disebabkan karena hasil pengamatan yang diperoleh antara LCD dengan mistar memiliki nilai yang cenderung lebih kecil dari jarak referensi. Maka agar mendekati jarak referensi, fungsi linear harus ditambahkan suatu konstanta yang bernilai positif. Hal ini disebabkan oleh pengulangan pembancaan yang konstan yaitu setiap 60 sekon, sehingga riak permukaan air yang terjadi saat pembacaan gelombang yang terpantul menuju receiver cenderung konstan. Sedangkan, berdasarkan Gambar 8(b), persamaan regresi yang diperoleh memiliki konstanta yang bernilai negatif yaitu -0,1677. Fungsi linear yang diperoleh memiliki konstanta yang bernilai negatif yaitu -0,1677. Sensor HC-SR04 akan efektif bekerja di jarak lebih dari $2 \mathrm{~cm}$. Sehingga pada jarak dibawah $2 \mathrm{~cm}$, nilai y pada persamaan regresi menjadi tidak stabil [11]. Selain itu, hasil pengamatan yang diperoleh antara pesan yang diterima pengguna dan mistar pada Tabel 3 memiliki nilai yang dominan lebih besar dibandingkan jarak referensi. Hal ini disebabkan oleh pengulangan pembacaan yang tidak konstan, pengulangan pembacaan terjadi saat pesan "cek" diterima oleh sistem. Saat pesan "cek" dikirimkan, butuh waktu sekitar 4 sekon untuk informasi ketinggian air saat itu diterima oleh pengguna. Pada interval waktu 4 sekon tersebut, riak permukaan air yang menjadi media pantul dari gelombang ultrasonik cenderung tidak konstan, hal ini yang menyebabkan nilai pembacaan jarak yang diterima oleh pengguna terkadang lebih besar maupun lebih kecil dari jarak referensi. Dikarenakan data yang diamati melalui SMS cenderung lebih besar dari jarak referensi, maka agar mendekati jarak referensi persamaan regresi harus ditambahkan suatu konstanta yang bernilai negatif. Oleh sebab itu, saat nilai x dimasukkan ke fungsi linear, kedua konstanta ini berperan menambahkan dan mengurangi hasil kali koefisien dengan $\mathrm{x}$ sehingga dalam memperoleh nilai y atau hasil regresi akan diperoleh hasil yang mendekati atau sama dengan jarak referensi. Berdasarkan Gambar 8(a) dan (b), terlihat bahwa alat memiliki akurasi yang baik. Hal tersebut ditunjukkan oleh kedekatan nilai pembacaan alat rancangan yang dibandingkan dengan nilai pembacaan pada mistar. Serta, dibuktikan dengan nilai koefisien determinasi $\left(\mathrm{R}^{2}\right)$ sebesar 0,9996 atau $99,96 \%$ untuk pembacaan melalui LCD dengan mistar dan $\mathrm{R}^{2}$ sebesar 0,9997 atau 99,97\% untuk pembacaan melalui pesan SMS dengan mistar. Kedekatan nilai tersebut mengindikasikan akurasi dari instrumen yang didesain [12]. 


\section{Kesimpulan}

Berdasarkan pada hasil penelitian dapat disimpulkan bahwa telah berhasil dirancang alat pendeteksi ketinggian air jarak jauh menggunakan sensor HC-SR04 dan modul GSM SIM800L berbasis mikrokontroler ATMEGA 328. Pengujian alat ukur dilakukan dengan membandingkan hasil yang terbaca di LCD dan melalui pesan yang diterima pengguna dengan alat ukur refrensi yaitu mistar. Hasil pengukuran dan analisis regresi menunjukkan hasil yang baik dibuktikkan dengan nilai koefisien determinasi $\left(\mathrm{R}^{2}\right)$ sebesar 0,9996 atau 99,96\% untuk pembacaan melalui LCD dengan mistar dan $\mathrm{R}^{2}$ sebesar 0,9997 atau 99,97\% untuk pembacaan melalui pesan SMS dengan mistar.

\section{Ucapan Terima Kasih}

Penulis menyampaikan terimakasih kepada staff dosen bidang minat Instrumentasi, Elektronika dan Komputasi, Prodi Fisika FMIPA, Universitas Udayana yang telah memberikan saran dan masukkan dalam penelitian ini.

\section{Pustaka}

[1] S.S. Mulyati, Internet of Thing (IoT) Pada Prototype Pendeteksi Kebocoran Gas Berbasis MQ-2 dan SIM800L, Jurnal Teknik: Universitas Muhammadiyah Tangerang, vol. 7, no. 2, 2018, pp. 64-72.

[2] J. Tarigan, A.D. Betan, R. Munadi, S. Syahreza, Sistem Peringatan Dini Banjir Berbasis Sms Gateaway dan Mikronktroler Arduino Uno, JTM-Jurnal Teknik Mesin, vol. 2, no. 2, 2017, pp. 6367.

[3] D. Satria, S.Yana, Sistem Perancangan Banjir Secara Dini Menggunakan Mikrokontroler Arduino Uno, Seminar Nasional II USM 2019, Banda Aceh, Universitas Serambi Mekkah, 2019.

[4] B.E. Cahyono, I.D. Utami, N.P. Lestari, N.S. Oktaviany, Karakterisasi Sensor LDR dan Aplikasinya pada Alat Ukur Tingkat Kekeruhan Air Berbasis Arduino UNO, Jurnal Teori dan Aplikasi Fisika, vol. 7, no. 2, 2019, pp. 179-186

[5] Bernandus., J. Tarigan, J. L. Tanesib, Perancangan Sistem Pendeteksi Banjir Dengan Menggunakan Sensor HC-SR04 Berbasis Arduino Uno, Jurnal Biotropikal Sains, vol. 16, no. 3, 2019, pp. 1-9.

[6] R. Sulistyowati, H.A. Sujono, A.K. Mustofa, Sistem Pendeteksi Banjir Berbasis Sensor Ultrasonik Dan Mikrokontroler dengan Media Komunikasi SMS Gate Way, Seminar Nasional Sains dan Teknologi Terapan III 2015, Surabaya, Institut Teknologi Adhi Tama Surabaya, 2017.

[7] M. Khaery, A.H. Pratama, P. Wipradnyana,A. A. N. Gunawan, Perancangan Alat Ukur Tekanan Udara Menggunakan Sensor Barimetric Pressure 280 (BMP280) Berbasis Arduino Uno, Buletin Fisika, vol. 21, no.1, 2020, pp.14-19.

[8] K.D. Wahyuadnyana, Modul GSM SIM800L Sebagai Pengontrol Jarak Jauh Sistem Otomatisasi Lampu dan Pendingin Ruangan Menggunakan Mikrokotroler ATMEGA 2560 Berbasis Short Message Sevice, Skripsi, Universitas Udayana, Bukit Jimbaran, 2019.

[9] Y. Mochtiarsa, B. Supriadi, Rancangan Kendali Lampu Menggunakan Mikrokontroller ATMega328 Berbasis Sensor Getar, Jurnal Informatika SIMANTIK, vol. 1, no.1, 2016, pp. 40-44

[10] Hanan, Sistem Pendeteksi Ketinggian Air Berbasis Sensor Ultrasonik HC-SR04 Dan Modul ESP8266-12e Dengan Media Komunikasi Telegram dan Buzzer, Skripsi, Universitas Udayana, Bukit Jimbaran, 2019.

[11] N.A. Karina, Perancangan Sistem Alir Larutan Nutrisi Otomatis Pada Tanaman Hidroponik Dengan Mikrokontroler Arduino Berbasis Android, Skripsi, Universitas Sumatera Utara, Medan, 2017.

[12] N.B. Prawira, A. Rouf, Perancangan Alat Ukur Massa Jenis Zat Cair Menggunakan Cepat Rambat Gelombang Ultrasonik, Indonesian Journal of Electronics and Instrumentation Systems (IJEIS), vol. 8, no. 2, 2018, pp: 134-154. 